\title{
Effect of Age on Flow-Rate, Protein and Electrolyte Composition of Stimulated Whole Saliva in Healthy, Non-Smoking Women
}

\author{
Liisi Sevón ${ }^{1, *}$, Merja A. Laine ${ }^{1}$, Sára Karjalainen ${ }^{2}$, Anguelina Doroguinskaia ${ }^{1}$, Hans Helenius ${ }^{3}$, \\ Endre Kiss ${ }^{4}$ and Marjo Lehtonen-Veromaa ${ }^{5}$
}

${ }^{I}$ Department of Periodontology, Institute of Dentistry, University of Turku, Finland; ${ }^{2}$ Department of Paediatric Dentistry, Institute of Dentistry, University of Turku, Finland; ${ }^{3}$ Department of Biomedical Sciences, University of Turku, Finland; ${ }^{4}$ Department of Periodontology, University of Szeged, Hungary and ${ }^{5}$ Public Health Center of Raisio, Finland

\begin{abstract}
As relatively little is known about the effect of age on salivary electrolytes we studied the composition of saliva as function of age to provide reference values for healthy non-smoking women. All non-medicated and non-smoking 3059 -year-old subjects $(n=255)$ selected from among 1030 women participating in a screening program formed the material of the present study. Salivary calcium, inorganic phosphate, magnesium, sodium, potassium, protein and flow-rate of stimulated whole saliva were measured. We found age-related changes in salivary calcium and phosphate concentrations $(\mathrm{p}=0.001$ and $\mathrm{p}=0.004$, respectively, one-way ANOVA). Peak values occurred at around 50-54 years of age. Age had no effect on flow-rate, magnesium, sodium, potassium or proteins. The concentration of sodium correlated positively, while phosphate, potassium, magnesium and protein correlated negatively with the salivary flow-rate. Calcium was the only electrolyte which had no association with flow-rate. Our study provides reference values for salivary electrolytes of 3059-year-old women.
\end{abstract}

Key Words: Salivary electrolytes, age, reference values.

\section{INTRODUCTION}

Salivary research is an important field of dentistry and oral biology. The significance of flow-rate and $\mathrm{pH}$ of saliva in the development of caries have been well-established already in the late 1970s and early 1980s [1]. Sex-dependent differences in flow rate [2] and calcium content of saliva [3, 4] have been observed. Clinically these findings suggest connections with caries on one hand and with chronic gingivitis and periodontitis on the other [4-7]. Apart from calcium there is little information about the association between salivary electrolytes and oral health. The significance of other electrolytes is unclear but it has been shown that medications can affect the composition of salivary electrolytes [8]. Moreover, the available textbook information on the concentration of inorganic components of whole saliva is mixed due to varying collection techniques [9]. Information on smoking or medications, factors known to affect the composition of saliva, are rarely given in the original publications cited in the review of Ferguson [9].

Earlier studies indicate that salivary calcium content increases with increasing flow-rate, as stimulation increases the calcium level of submandibular saliva $[10,11]$. Yet, our follow-up study on stimulated whole saliva of menopausal women demonstrated that salivary flow-rate and calcium content are not directly correlated [12]. It is known that estrogens affect oral health in a number of ways, and saliva

\footnotetext{
*Address correspondence to this author at the Institute of Dentistry, University of Turku, Lemminkäisenkatu 2, FIN-20520 Turku, Finland, Tel: + 3582-333 8335, Fax: +358-2-333 8356; E-mail: liisi.sevon@utu.fi
}

undergoes variations during e.g. pregnancy and menopause $[13,14]$. Dry mouth is a common complaint among older women. Aging process, however, is not the primary cause of reduced salivary flow rate [2], but secondary to various diseases and/or medications [2]. Therefore reference values for organic and inorganic composition of saliva are needed. There are only few age-related salivary studies on nonmedicated subjects, but to our knowledge no salivary studies exist excluding both the effects of medications and smoking.

Our aim was to study the effect of age on salivary flow rate, the level of calcium, phosphate, magnesium, sodium and potassium in healthy women. These results can be used as reference values for 30-59-year-old women.

\section{MATERIALS AND METHODS}

Originally our study group consisted of 1030 women (age range 30-62 years) participating in a pre-screen referral program for osteoporosis. The screening was carried out by the Public Health Centre of Raisio, a South-Western Finnish community with a population of 23000 inhabitants. The age cohorts invited in 1999 included all women living in the community and born in the years 1940, 1941, 1943, 1945, 1949, 1954, 1957, 1959, 1964 and 1969. There was one subject born in 1937 who participated in the screening but was excluded from the present study. Women with verified $(n=12)$ and uncertain pregnancies $(n=3)$ were excluded. A brief medical history including medications and smoking habits were recorded by a questionnaire filled out by all consenting participants before screening. All participants having one or several systemic diseases or using medications includ- 
ing hormone replacement therapy were excluded. Women who reported of smoking habits were also excluded. The age distribution of the remaining healthy, non-medicated, nonsmoking subjects $(n=255,30-59$ years $)$ is presented in Table 1. The women were further divided in subgroups at five-year intervals.

Table 1. Frequency Distribution and Salivary Flow Rate of Healthy, Non-Medicated and Non-Smoking Women According to Age Groups. The p-Value for Variations in Flow Rate was 0.128 (One-way ANOVA)

\begin{tabular}{|c|c|c|}
\hline Age Groups & $\mathbf{N}$ & $\begin{array}{c}\text { Flow Rate } \mathbf{m l} \text { /min } \\
\text { Mean (SD) (Min-Max) }\end{array}$ \\
\hline \hline $30-34$ & 23 & $1.4(0.6)(0.5-3.0)$ \\
\hline $35-39$ & 28 & $1.8(0.7)(0.8-3.4)$ \\
\hline $40-44$ & 44 & $1.4(0.6)(0.6-3.2)$ \\
\hline $45-49$ & 54 & $1.4(0.6)(0.4-3.1)$ \\
\hline $50-54$ & 69 & $1.6(0.8)(0.3-4.0)$ \\
\hline $55-59$ & 37 & $1.6(0.7)(0.4-3.2)$ \\
\hline TOTAL & 255 & $1.5(0.7)(0.3-4.0)$ \\
\hline
\end{tabular}

The study was approved by the ethics committee of the municipality of Raisio. The subjects were volunteers and informed consent was obtained from all participants.

The participants refrained from tooth brushing, eating, and drinking for a minimum of one hour prior to saliva collection. The collection procedure of the saliva samples was standardized prior the study. The samples were collected around noon in field conditions without any laboratory equipments at the collection site. Stimulated whole saliva was collected by chewing a piece of paraffin-wax $(1 \mathrm{~g})$ at habitual pace. After $60 \mathrm{~s}$ of pre-stimulation, the secreted saliva was spat in graded disposable plastic cups for 5 minutes. The flow rate was measured and expressed as $\mathrm{ml} / \mathrm{min}$. The samples were transferred to test tubes immediately after collection, put on ice, frozen and stored at $-20^{\circ} \mathrm{C}$ until further analysis.
Calcium, magnesium, potassium and sodium concentrations were measured by atomic absorption spectrophotometer (Perkin-Elmer Atomic Absorption Spectrophotometer Model 303, Norwalk, USA). Due to the strong affinity of calcium to form complexes with salivary proteins, noncentrifuged whole saliva containing both protein-bound and soluble calcium was used for the assay. All other analytical procedures were carried out using centrifuged (12 $000 \mathrm{~g}, 10$ $\min +4^{\circ} \mathrm{C}$ ) and diluted samples as recommended by the manufacturer [15]. Inorganic phosphate was analyzed according to Kallner [16] and total protein according to Lowry et al. [17], both from centrifuged saliva.

The normality of distributions of the response variables were controlled by the Kolmogorov-Smirnov test. Before statistical analyses, logarithmic transformations of the salivary variables were made due to the skewed distributions. The statistical evaluations were performed by one-way analysis of variance. Correlations between flow rate and salivary constituents were measured by Pearson's correlation coefficients. A commercial software program (Statistical Package for Social Sciences for Windows, version 9.0, SPSS Inc., Chicago, Illinois, USA) was used to run the statistical analyses.

\section{RESULTS}

The average flow rates of paraffin-stimulated saliva in the six age groups varied from $1.4( \pm 0.6)$ to $1.8( \pm 0.7) \mathrm{ml} /$ min, yielding an average of $1.5( \pm 0.7) \mathrm{ml} / \mathrm{min}$ for the whole study group (Table 1). The average flow rate of the second age group (35-39) was slightly higher than the rest of the age groups but the difference was not significant $(\mathrm{p}=0.182)$.

Salivary calcium and phosphate concentrations showed a clear increase with increasing age (Table 2). Peak values occurred at around 50-54 years of age. Calcium and phosphate increased about $12 \%$ at the age group of 50-54 years as compared to the younger age group from 45 to 49 years.

Salivary flow rate correlated negatively with magnesium, potassium, and phosphate, and with the protein level and positively with sodium. Calcium was the only electrolyte which did not show correlation with flow rate (Table $\mathbf{3}$ ).

Means and standard deviations (SD) of salivary flow rate, sodium, potassium, magnesium concentrations and protein

Table 2. Salivary Calcium and Phosphate in 30-59-Year-Old Non-Medicated and Non-Smoking Women. The Age-Related $p$ Values for Calcium and Phosphate were 0.001and 0.004, Respectively (One-way ANOVA)

\begin{tabular}{|c|c|c|c|c|c|c|}
\hline Age Group & $\begin{array}{c}\text { Calcium }(\mathrm{mmol} / \mathrm{l}) \\
\operatorname{Mean}(\mathrm{SD})\end{array}$ & $\begin{array}{c}2.5 \\
\text { Percentile }\end{array}$ & $\begin{array}{c}97.5 \\
\text { Percentile }\end{array}$ & $\begin{array}{c}\text { Phosphate (mmol/l) } \\
\text { Mean (SD) }\end{array}$ & $\begin{array}{c}2.5 \\
\text { Percentile }\end{array}$ & $\begin{array}{c}97.5 \\
\text { Percentile }\end{array}$ \\
\hline $30-34$ & $1.24(0.26)$ & 0.82 & 1.82 & $3.77(1.00)$ & 2.38 & 6.32 \\
\hline $35-39$ & $1.16(0.23)$ & 0.87 & 1.71 & $3.37(1.00)$ & 1.43 & 5.10 \\
\hline $40-44$ & $1.40(0.37)$ & 0.73 & 2.15 & $3.82(0.89)$ & 2.27 & 5.82 \\
\hline $50-54$ & $1.73(0.41)$ & 1.20 & 2.52 & $4.38(1.57)$ & 2.32 & 8.95 \\
\hline $55-59$ & $1.61(0.29)$ & 1.15 & 2.42 & $4.04(1.27)$ & 1.57 & 8.47 \\
\hline
\end{tabular}


content and $97.5 \%$ and $2.5 \%$ percentiles of all age groups are given in Table 4.

Table 3. Correlations between Salivary Flow Rate and Calcium, Phosphate, Magnesium, Sodium, Potassium and Protein

\begin{tabular}{|c|c|c|}
\hline & $\begin{array}{c}\text { Pearson's Correlation } \\
\text { (p-Value) }\end{array}$ & $\begin{array}{c}\text { Regression } \\
\text { Coefficient }\end{array}$ \\
\hline \hline Calcium (mmol/l) & $0.02(0.750)$ & 0.071 \\
\hline Phosphate (mmol/l) & $-0.33(0.000)$ & -3.764 \\
\hline Magnesium (mmol/l) & $-0.34(0.000)$ & -0.144 \\
\hline Sodium (mmol/l) & $0.40(0.000)$ & 17.85 \\
\hline Potassium (mmol/l) & $-0.31(0.000)$ & -10.07 \\
\hline Proteins $(\mathrm{g} / \mathrm{l})$ & $-0.25(0.000)$ & -0.025 \\
\hline
\end{tabular}

our study, which did not correlate with salivary flow-rate. This is in contrast to earlier studies showing an increase in salivary calcium with short-term citric acid stimulation of parotid saliva [11].

According to our study, salivary calcium and phosphate concentrations increase with age showing peak values around menopause. Therefore we suggest that menopause is reflected in saliva as elevated levels of calcium and phosphate. This result is well in accordance with our earlier findings [12]. The reason why salivary calcium seems to increase with age may be explained by the hypothesis we have presented earlier for smokers: we were suggesting that a decrease in skeletal bone density, frequently detected in elderly people, may increase the amount of calcium in saliva [19]. However, this phenomenon is not completely clear and needs further studies. We have data on salivary calcium of different study populations with decreasing bone mineral density, such as patients with rheumatoid arthritis [20], heavy smokers [19] and women in menopausal ages [12]. They all have higher means of salivary calcium level when compared to age-matched counterparts. We have also found

Table 4. Means, Standard Deviations and 2.5 and 97.5 Percentiles of Salivary Flow Rate, Sodium, Potassium, Magnesium and Protein of 255 Non-Smoking and Non-Medicated Subjects

\begin{tabular}{|c|c|c|c|}
\hline & Mean (SD) & 2.5 Percentile & 97.5 Percentile \\
\hline \hline Flow rate $(\mathrm{ml} / \mathrm{min})$ & $1.5(0.7)$ & 0.4 & 3.2 \\
\hline Sodium $(\mathrm{mmol} / \mathrm{l})$ & $10.8(6.7)$ & 2.8 & 27.1 \\
\hline Potassium $(\mathrm{mmol} / \mathrm{l})$ & $18.5(3.4)$ & 10.9 & 25.5 \\
\hline Magnesium $(\mathrm{mmol} / \mathrm{l})$ & $0.104(0.060)$ & 0.039 & 0.221 \\
\hline Protein $(\mathrm{g} / \mathrm{l})$ & $1.21(0.34)$ & 0.70 & 2.06 \\
\hline
\end{tabular}

\section{DISCUSSION}

To our knowledge this is the first time when salivary composition has been studied for reference purposes in nonmedicated and non-smoking women to this extent. We are providing values for randomly selected subjects, contrary to many earlier studies. The main difficulties in salivary research of adult and elderly population are the great interindividual variation, the increasing number of subjects using medications and having diseases affecting salivary flow and composition. Only $22 \%$ of the initial study group of 1030 women met our strict criteria. Flow-rate correlated positively with sodium and negatively with phosphate, potassium, magnesium and protein, which is partly in line with the most recent text-book data [9]. However, some of our findings are controversial as compared to earlier reports: we found that salivary potassium was negatively correlated with flow rate as opposed to earlier reports [18] showing that potassium after a 2-3 minutes' continued stimulation reached a constant value. This may be due to two reasons: firstly, we studied whole saliva while the results of the study above [18] apply to parotid saliva, and secondly we made inter-individual comparisons as opposed to the study-design above [18] where intra-individual variations are presented as function of prolonged stimulation. Calcium was the only electrolyte in that hormone replacement therapy, which has a stabilizing effect on calcium content of bone, has a similar effect on salivary calcium [12].

Earlier it was generally believed that salivary flow rate decreases with age, but increasing number of studies are showing that aging does not affect the rate of stimulated whole saliva. Our current finding of no correlation between age and salivary flow-rate is well in line with the works of Parvinen and Larmas [2], Tylenda et al. [21], and with the more recent studies of Närhi et al. [22], Percival et al. [23], and Yeh et al. [24].

To conclude, we found that age had no effect on the flow-rate of stimulated saliva. However, salivary calcium and phosphate concentrations increased with age showing peak values around 50 years of age. In addition, normal reference values of salivary electrolytes of different age groups are provided for women to enable future diagnostic use of salivary electrolytes.

\section{REFERENCES}

[1] Edgar M, Dawes C, O'Mullane D: Factors influencing salivary flow rate and composition. In: Saliva and dental health, $3^{\text {rd }}$ ed. $\odot$ Br Dent J 2004; pp. 32-49. 
[2] Parvinen T, Larmas M. Age dependency of stimulated salivary flow rate, $\mathrm{pH}$ and lactobacillus and yeast concentrations. J Dent Res 1982; 61: 1052-5.

[3] Sewón L, Karjalainen S, Sainio M, Seppä O. Calcium and other salivary factors in periodontitis-affected subjects prior to treatment. J Clin Periodontol 1995; 22: 267-70.

[4] Sewón L, Karjalainen S, Söderling E, Lapinleimu H, Simell O. Associations between salivary calcium and oral health. J Clin Periodontol 1998; 25: 915-9.

[5] Ashley F, Coward P, Jalil R, Wilson R. Relationship between calcium and inorganic phosphorous concentrations of both resting and stimulated saliva and dental plaque in children and young adults. Arch Oral Biol 1991; 36: 431-4.

[6] Mandel I. Biochemical aspects of calculus formation II. Comparative studies of saliva in heavy and light calculus formers. J Periodontal Res 1974; 9: 211-21.

[7] Sewón L, Mäkelä M. A study of the possible correlation of high salivary calcium levels with periodontal and dental conditions in young adults. Arch Oral Biol 1990; 35: Suppl. 211-2.

[8] Nederfors T, Dahlöf C. Effects of beta-adrenoceptor antagonists atenolol and propanolol on human whole saliva flow rate and composition. Arch oral Biol 1992; 37: 579-84.

[9] Ferguson DB. Salivary electrolytes. In: Tenovuo J, editor. Human saliva: Clinical chemistry and microbiology. Volume I. CRC Press. 1989; pp. 76-88.

[10] Dawes C. The effects of flow rate and duration of stimulation on the concentrations of protein and the main electrolytes in human parotid saliva. Arch Oral Biol 1969; 14: 277-94.

[11] Dawes C. The effects of flow rate and duration of stimulation on the concentrations of protein and the main electrolytes in human submandibular saliva. Arch Oral Biol 1974; 19: 887-95.

[12] Sewón L, Laine M, Karjalainen S, Leimola-Virtanen R, Hiidenkari $\mathrm{T}$, Helenius $\mathrm{H}$. The effect of hormone replacement therapy on salivary calcium concentrations in menopausal women. Arch Oral Biol 2000; 45: 201-6.
[13] Laine M, Tenovuo J, Lehtonen O-P, Ojanotko-Harri A, Vilja P, Tuohimaa P. Pregnancy related changes in human whole saliva. Arch Oral Biol 1988; 33: 913-7.

[14] Parvinen T. Flow rate, $\mathrm{pH}$ and lactobacillus and yeast counts of stimulated whole saliva in adults. Proc Finn Dent Soc Thesis.1985 80: Suppl.10

[15] Perkin-Elmer Manual: Analytical methods for Atomic Absorption Spectrophotometry. 1976.

[16] Kallner A. Determination of phosphate in serum and urine by single step malachite- green method. Clin Chim Acta 1975; 59: 35-9.

[17] Lowry O, Rosebrough N, Farr A, Randall R. Protein measurement with the Folin-phenol reagent. J Biol Chem 1951; 193: 265-75.

[18] Dawes C. The effects of flow rate and duration of stimulation on the concentrations protein and the main electrolytes in human parotid saliva. Arch Oral Biol 1969; 14: 277-94

[19] Sewón L, Laine M, Karjalainen S, Doroguinskaia A, LehtonenVeromaa M. Salivary calcium reflects skeletal bone density of heavy smokers. Arch Oral Biol 2004; 49: 355-8.

[20] Sewón L, Hyyppä T, Paunio K. Flow-rate and electrolytes of saliva in rheumatoid arthritis patients. J Dent Res Spec Iss 1993; 72: 404.

[21] Tylenda CA, Ship JA, Fox PC, Baum BJ. Evaluation of submandibular salivary flow rate in different age groups. J Dent Res 1988 67: $1225-8$

[22] Närhi T, Meurman J, Ainamo A, et al. Association between salivary flow rate and the use of systemic medication among 76-81-, and 86-year-old inhabitants in Helsinki, Finland. J Dent Res 1992; 71: 1875-80.

[23] Percival RS, Challacombe SJ, Marsh PD. Flow rates of resting whole and stimulated parotid saliva in relation to age and gender. J Dent Res 1994; 73: 1416-20.

[24] Yeh CK, Johnson DA, Dodds MW. Impact of aging on human salivary gland function: a community-based study. Aging (Milano). 1998; 10: 421-8

(C) Sevón et al.; Licensee Bentham Open.

This is an open access article distributed under the terms of the Creative Commons Attribution License (http://creativecommons.org/licenses/by/2.5/), which permits unrestrictive use, distribution, and reproduction in any medium, provided the original work is properly cited. 